\title{
Assessment of suitability of screen tubes with damages for further use on the basis of mathematical modeling
}

\author{
Drobenko B., Budz S. \\ Pidstryhach Institute for Applied Problems of Mechanics and Mathematics \\ National Academy of Sciences of Ukraine, \\ 3-b Naukova Str., 79060, Lviv, Ukraine
}

(Received 23 April 2019; Revised 29 May 2019; Accepted 30 May 2019)

\begin{abstract}
Computer simulation of the processes of deformation of screen tubes of boiler units at a thermal power station with wall thinning due to the intense influence of flue gases has been carried out. The dependences between the maximum stresses in the screen tubes with operational thinnings and the geometrical parameters of the damaged areas of the tubes have been constructed, which allow us to determine the minimum thickness of tubes, for which operating stresses do not exceed a given permissible level. The minimum permissible thickness of the tube in the middle zone of the damaged area has been established. It is shown that the temperature stresses in a pipe under its external heating somewhat compensate for force stresses from the internal pressure.
\end{abstract}

Keywords: mathematical and computer modeling, tubes of boiler units, assessment of suitability for operation, stress state, rational geometric parameters.

2000 MSC: $74 \mathrm{~A} 10,74 \mathrm{~B} 10$

UDC: $539.3,518.61,658.589$

DOI: $10.23939 / \mathrm{mmc} 2019.01 .021$

\section{Introduction}

During operation of power units of a thermal power station (TPS), an intensive corrosion processes occur in the metal of the structural elements of the boiler units [1,2], in particular, screen tubes undergo corrosion-erosion wear caused by the action of the flue gas.

The Burshtyn TPS has accumulated considerable experience in identifying and assessment of the rate of development of such damages, their location on the screen tubes, etc. During the scheduled repairs of the boilers, visual inspection of the affected areas is carried out as well as the ultrasonic thickness measurement of tubes, which results in a replacement of a large number of worn tubes, which requires significant labor efforts and financial costs. At the same time, the substantiation for making decisions on the continuation of operation of the pipes or their replacement is the estimation of the stresses in a zone of the thinning of a pipe under in-service conditions.

The existing techniques for calculating stresses in screen tubes under operational conditions use the hypothesis that the thickness of their walls is homogeneous. According to the branch standard OCT 108.031.02-75, the maximum stresses $\sigma_{\max }$ in the screen tubes are determined on the basis of the relationships obtained for the calculation of a thin cylindrical tube with the thickness of the wall $s$ under the action of internal pressure $p$

$$
\sigma_{\max }=\frac{p R}{s},
$$

where $R$ is the outside radius of the tube. At the same time for the thickness $s$, they take the minimum thickness of the pipe wall at the site of damage. Such an approach does not take into account the influence of the geometric shape of the damaged area on the stresses.

However, under the corrosion or corrosion-erosion wear are the local areas of the outer surface of tubes with varying lengths along the length of the tubular elements, which changes the geometric shape 
of the tube. In places of local thickness, the level and distribution of operational stresses may differ significantly from those obtained on the basis of the relationship (1).

The issue is also important to determine the thermal stresses arising from the operation of screen tubes and to assess their contribution to the general stressed state. The solution of these issues is related to the problem of rational operation and prolongation of the terms of service of the elements of power equipment.

The purpose of this work is to develop a refined method for determining the stress state of screen tubes with a damaged near-surface area and on this basis to determine permissible in terms of stresses the geometric parameters (depth, width, and length) of damage of a near-surface zone.

\section{Formulation of the problem and assumptions made}

Let us consider an screen tube with a damaged near-surface area.

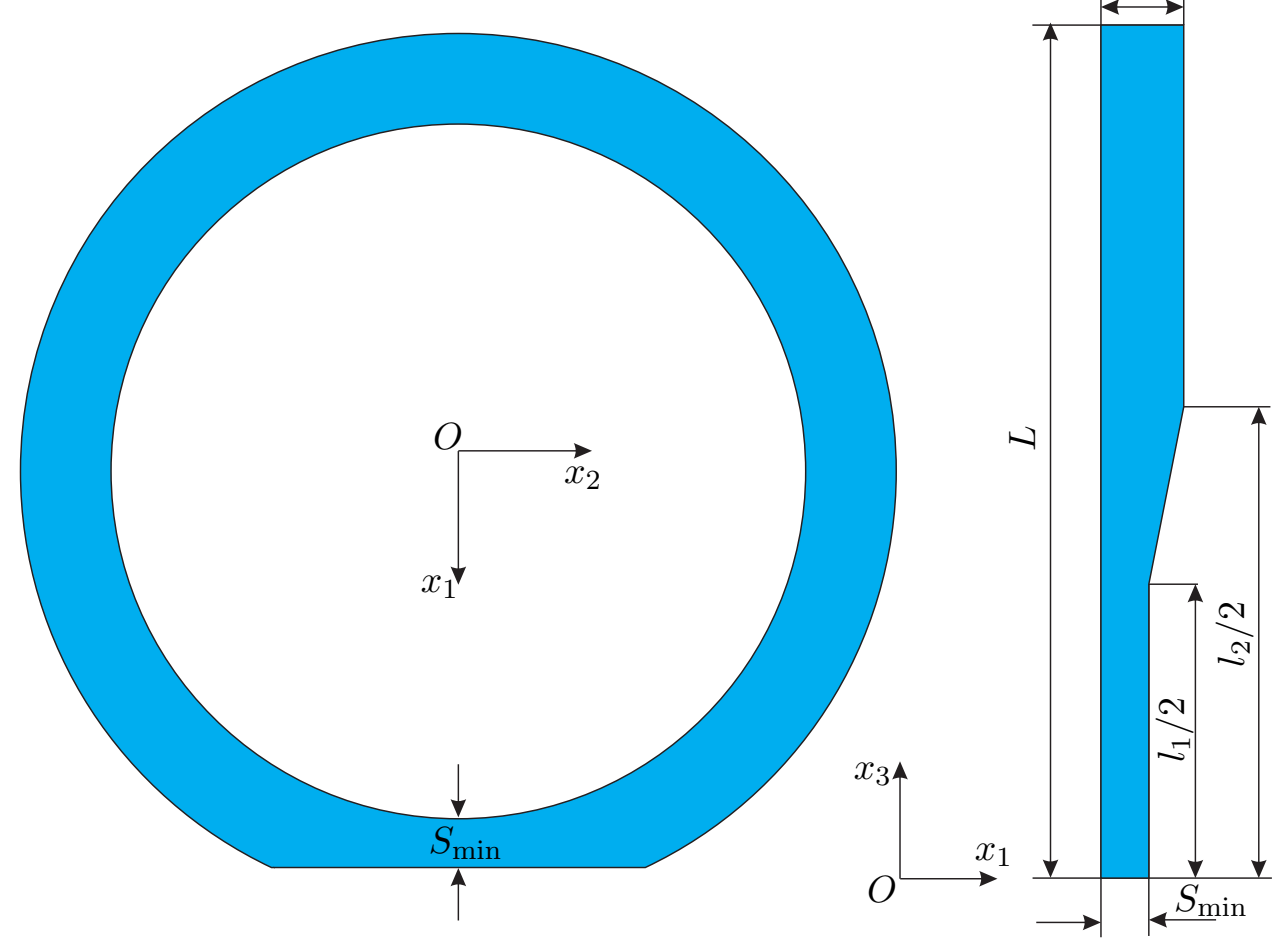

Fig. 1. Cross-section of the three-dimensional model of screen tube by planes $x_{3}=0$ and $x_{2}=0$.

In order to more adequately describe the geometry of the damaged area and study the influence of the geometrical parameters of damage on the stress state of the tube, we consider the tube as an elastic three-dimensional body. The zone of damage is modeled as a cut-off near-surface area, as shown in Fig. 1, which has a known depth, width, and length (outside the damage zone $\left|x_{3}\right|>0.5 l_{2}$, we have a hollow circular cylinder with the constant thickness $\left.s_{0}\right)$.

The choice of this geometric shape of the damaged site is due to the fact that in practical inspections of screen tubes, most often damages are indicated that resemble the circular segment. It should be noted that this developed technique gives us an opportunity to estimate the stressed state of tubes with other forms of the external surface.

Within the framework of the general statement of the problem, we assume that the considered body is in the condition of a given temperature drop in the thickness, on its inner surface the hydrostatic pressure $p$ acts, and the external surface is free of mechanical loads. We solve this problem under the assumption that the ends of the cylinder (when $\left|x_{3}\right|=L$ ) are free from axial loads. From the conditions of symmetry (relative to planes $x_{3}=0$ ), we consider only half the body. 


\section{The basic determining relationships}

Let us determine the stress-strain state of the body, namely, the components $u_{i}, \varepsilon_{i j}$ and $\sigma_{i j}$ of the vector of displacements $u$ and of the symmetric tensors of deformation $\varepsilon$ and stresses $\sigma$, respectively, which we find from the Cauchy's geometric relationships

$$
\varepsilon_{i j}=\frac{1}{2}\left(\frac{\partial u_{i}}{\partial x_{j}}+\frac{\partial u_{j}}{\partial x_{i}}\right)
$$

from the equations of state

$$
\sigma_{i j}=a_{i j k m}\left(\varepsilon_{k m}-\delta_{i j} \alpha_{t} T\right)
$$

and from the equations of equilibrium

$$
\frac{\partial \sigma_{i j}}{\partial x_{j}}+F_{i}=0, \quad r \in \Omega
$$

under the boundary conditions

$$
\begin{aligned}
& n_{i} \sigma_{i j}-p_{i}=0, \quad \boldsymbol{r} \in S_{\sigma}, \\
& u_{i}=u_{i}^{*}, \quad \boldsymbol{r} \in S_{u} .
\end{aligned}
$$

Here $\Omega$ is the area of space occupied by the body; $i, j, k, m=1,2,3 ; \boldsymbol{r}$ is the radius vector of the point $\left(x_{1}, x_{2}, x_{3}\right) ; F_{i}, n_{i}$ are the components of the vectors of mass forces $\boldsymbol{F}$ and of the unit vector $\boldsymbol{n}$ normal to the surface; $S=S_{u} \cup S_{\sigma}\left(S_{u} \cap S_{\sigma}=\varnothing\right) ; a_{i j k m}$ are the elastic constants, which in the case of an isotropic body are related to the Young's modulus $E$ and the Poisson's ratio $\nu ; \delta_{i j}$ is the Kronecker delta; $\alpha_{T}$ is the coefficient of temperature expansion; $T$ is temperature (in the presented expressions, the repeating indices are summation indices).

The temperature field in the body is determined from the stationary heat equation

$$
\boldsymbol{\nabla} \cdot[\lambda \nabla T]=0 .
$$

at given temperatures on the inner and outer surfaces of the cylinder. Here $\boldsymbol{\nabla}$ is the nabla operator; $\lambda=\lambda(T)$ is the coefficient of thermal conductivity.

The relationships (2)-(4) with the boundary conditions (5), (6) constitute the complete system of equations of the stationary problem of the theory of elasticity, for which there is a unique solution [3-7]. Since it is not always possible to obtain it in an analytical form for bodies of complex geometric configuration, we use a numerical approach, developed on the basis of the finite element method $[9,10]$, to solve the formulated problem. In this case, the variational formulation of the problem of the theory of elasticity is natural. With this purpose, we write the basic relationships of the theory of elasticity in the matrix form [9]. In order to do this, we introduce vectors of stresses and deformations

$$
\begin{aligned}
\{\sigma\} & =\left(\sigma_{11}, \sigma_{22}, \sigma_{33}, \sigma_{12}, \sigma_{13}, \sigma_{23}\right)^{\mathrm{T}} ; \\
\{\varepsilon\} & =\left(\varepsilon_{11}, \varepsilon_{22}, \varepsilon_{33}, 2 \varepsilon_{12}, 2 \varepsilon_{13}, 2 \varepsilon_{23}\right)^{\mathrm{T}} ; \\
\left\{\varepsilon_{t}\right\} & =\left(\alpha_{t} T, \alpha_{t} T, \alpha_{t} T, 0,0,0\right)^{\mathrm{T}},
\end{aligned}
$$

as well as matrices of elastic constants

$$
[\boldsymbol{D}]=\frac{E}{(1+\nu)(1-2 \nu)}\left[\begin{array}{cccccc}
1-\nu & \nu & \nu & 0 & 0 & 0 \\
\nu & 1-\nu & \nu & 0 & 0 & 0 \\
\nu & \nu & 1-\nu & 0 & 0 & 0 \\
0 & 0 & 0 & (1-2 \nu) / 2 & 0 & 0 \\
0 & 0 & 0 & 0 & (1-2 \nu) / 2 & 0 \\
0 & 0 & 0 & 0 & 0 & (1-2 \nu) / 2
\end{array}\right]
$$

Mathematical Modeling and Computing, Vol.6, No. 1, pp. 21-29 (2019) 
the differential operator of the geometric relations of the theory of elasticity

$$
[\boldsymbol{B}]^{\mathrm{T}}=\left[\begin{array}{cccccc}
\frac{\partial}{\partial x_{1}} & 0 & 0 & \frac{\partial}{\partial x_{2}} & \frac{\partial}{\partial x_{3}} & 0 \\
0 & \frac{\partial}{\partial x_{2}} & 0 & \frac{\partial}{\partial x_{1}} & 0 & \frac{\partial}{\partial x_{3}} \\
0 & 0 & \frac{\partial}{\partial x_{3}} & 0 & \frac{\partial}{\partial x_{1}} & \frac{\partial}{\partial x_{2}}
\end{array}\right],
$$

and directing cosines of the external normal to the surface

$$
[\boldsymbol{A}]=\left[\begin{array}{ccc}
n_{1} & 0 & 0 \\
0 & n_{2} & 0 \\
0 & 0 & n_{3} \\
n_{2} & n_{1} & 0 \\
n_{3} & 0 & n_{1} \\
0 & n_{3} & n_{2}
\end{array}\right]
$$

Taking into account the introduced notation, the relationships (2)-(6) take the following forms

$$
\begin{aligned}
& \{\varepsilon\}=[\boldsymbol{B}] \boldsymbol{u}, \\
& \{\sigma\}=[\boldsymbol{D}]\left(\{\varepsilon\}-\left\{\varepsilon_{t}\right\}\right), \\
& {[\boldsymbol{B}]^{\mathrm{T}}\{\sigma\}+\boldsymbol{F}=\mathbf{0}, \quad \boldsymbol{r} \in \Omega,} \\
& {[\boldsymbol{A}]^{\mathrm{T}}\{\sigma\}=\boldsymbol{p}, \quad \boldsymbol{r} \in S_{\sigma} .}
\end{aligned}
$$

In accordance with the Lagrange variational principle $[3,5,9]$, the displacements corresponding to the equilibrium state are determined from the condition of the minimum of the functional of the energy of elastic deformation

$$
\Pi(\boldsymbol{u})=\frac{1}{2} \int_{\Omega}\{\varepsilon\}^{\mathrm{T}}\{\sigma\} d v-\int_{S_{\sigma}} \boldsymbol{u}^{\mathrm{T}} \boldsymbol{p} d s-\int_{\Omega} \boldsymbol{u}^{\mathrm{T}} \boldsymbol{F} d v
$$

on the set

$$
V=\left\{\boldsymbol{u}=\left(u_{1}, u_{2}, u_{3}\right)^{\mathrm{T}}: u_{i}=u_{i}^{*}, \boldsymbol{r} \in S_{u}, u_{i} \in H^{1}(\Omega)\right\},
$$

where $H^{1}(\Omega)$ is a Sobolev space, which consists of functions, all partial derivatives of which (in the sense of generalized functions) of the first order, as well as the functions, are Lebesgue integrable with squares on $\Omega$.

Taking into account (8) and (9), the Lagrangian functional has the form

$$
\Pi(\boldsymbol{u})=\frac{1}{2} \int_{\Omega} \boldsymbol{u}^{\mathrm{T}}[\boldsymbol{B}]^{\mathrm{T}}[\boldsymbol{D}][\boldsymbol{B}] \boldsymbol{u} d v-\frac{1}{2} \int_{\Omega} \boldsymbol{u}^{\mathrm{T}}[\boldsymbol{B}]^{\mathrm{T}}[\boldsymbol{D}]\left\{\varepsilon_{t}\right\} d v-\int_{S_{\sigma}} \boldsymbol{u}^{\mathrm{T}} \boldsymbol{p} d s-\int_{\Omega} \boldsymbol{u}^{\mathrm{T}} \boldsymbol{F} d v .
$$

In this formulation, the problem of determining the stress-strain state of the considered body under the action of the force and temperature loads is reduced to determining the minimum of the functional (13) on the set $\Omega$. In other words, we set for the boundary value problem (1)-(5) the variational problem into conformity

$$
\Pi(\boldsymbol{u}) \underset{\boldsymbol{u} \in V}{\longrightarrow} \min ,
$$

from the solutions of which we obtain the displacement (three functions $u_{1}, u_{2}, u_{3}$ ). For the known displacements from the relationship (1), we determine the deformations (six functions $\varepsilon_{11}, \varepsilon_{22}, \varepsilon_{33}, \varepsilon_{12}$, $\varepsilon_{13}, \varepsilon_{23}$ ), and then, in accordance with the relationships (2), we obtain the stresses (six functions $\sigma_{11}$, $\left.\sigma_{22}, \sigma_{33}, \sigma_{12}, \sigma_{13}, \sigma_{23}\right)$, as well as the intensity of stresses

$$
\begin{gathered}
\sigma_{i}=\sqrt{\frac{3}{2} \cdot\left[\left(\sigma_{11}-\sigma_{m}\right)^{2}+\left(\sigma_{22}-\sigma_{m}\right)^{2}+\left(\sigma_{33}-\sigma_{m}\right)^{2}+\sigma_{12}^{2}+\sigma_{13}^{2}+\sigma_{23}^{2}\right]} \\
\left(\sigma_{m}=\sigma_{11}+\sigma_{22}+\sigma_{33}\right) .
\end{gathered}
$$


The formulated problem of determining the stressed state of the considered body we solve by using the finite element method. In accordance with the concept of this method $[9,10]$, the considered body is represented as a combination of simple sub-areas (finite elements) with the introduction of an appropriate approximation of their geometric configuration and the desired functions within these subareas. Passing an element by element and summing up the contributions of each individual finite element, we obtain the total potential energy of the body

$$
\Pi(\boldsymbol{Q})=\frac{1}{2} \boldsymbol{Q}^{\mathrm{T}}[\boldsymbol{K}] \cdot \boldsymbol{Q}-\boldsymbol{Q}^{\mathrm{T}} \boldsymbol{f}
$$

where $\boldsymbol{Q}$ is a vector of displacements of the nodes of finite element division of the body; $[\boldsymbol{K}], \boldsymbol{f}$ are the matrix of rigidity and the vector of forces, which we obtain by summing up the corresponding matrix-vector characteristics of the individual elements, which, for isoparametric finite elements [9], take the form

$$
\begin{aligned}
& \qquad \boldsymbol{K}]_{(e)}=\int_{-1}^{1} \int_{-1}^{1} \int_{-1}^{1}\left[\boldsymbol{B}_{\xi} \boldsymbol{N}\right]^{\mathrm{T}}[\boldsymbol{D}]\left[\boldsymbol{B}_{\xi} \boldsymbol{N}\right] \operatorname{det}[J] d \xi_{1} d \xi_{2} d \xi_{3} \\
& \boldsymbol{f}_{(e)}=\int_{-1}^{1} \int_{-1}^{1} \int_{-1}^{1}\left[\boldsymbol{B}_{\xi} \boldsymbol{N}\right]^{\mathrm{T}}[\boldsymbol{D}]\left\{\varepsilon_{t}\right\} \operatorname{det}[J] d \xi_{1} d \xi_{2} d \xi_{3} \\
& +\int_{-1}^{1} \int_{-1}^{1} \int_{-1}^{1}[\boldsymbol{N}]^{\mathrm{T}} \boldsymbol{F} \operatorname{det}[J] d \xi_{1} d \xi_{2} d \xi_{3}+\int_{-1}^{1} \int_{-1}^{1}[\boldsymbol{N}]^{\mathrm{T}} \boldsymbol{p} \sqrt{E_{1} E_{2}-E_{12}^{2}} d \xi_{1} d \xi_{2}
\end{aligned}
$$

where the matrix $\left[\boldsymbol{B}_{\xi} \boldsymbol{N}\right]$ is obtained by multiplying the matrix $[\boldsymbol{B}]$, written in the local coordinate system $\xi_{i}$ of the finite element, by the matrix of functions of the form $[\boldsymbol{N}][9,10]$; $\operatorname{det}[J]$ is a determinant of the Jacobi matrix of transition from global coordinates to local coordinates,

$$
E_{1}=\sum_{i=1}^{3} J_{1 i}^{2} ; \quad E_{2}=\sum_{i=1}^{3} J_{2 i}^{2} ; \quad E_{12}=\sum_{i=1}^{3} J_{1 i} J_{2 i} .
$$

Using the necessary condition for minimizing potential energy, we arrive at the system of linear algebraic equations

$$
[\boldsymbol{K}] \cdot \boldsymbol{Q}=\boldsymbol{f}
$$

with respect to the unknown displacements in the nodes of finite-element division of the body.

Similarly, using the concept of the finite element method, we obtain the solution of the temperature problem (Eq. (7) at given temperatures on the inner and outer surfaces of the considered body). Thus, the matrix of the system of linear algebraic equations with respect to the temperature values in the nodes of division of the body into finite elements is obtained by summing up the corresponding matrices of the individual elements of the form

$$
\left[\boldsymbol{K}_{\mathrm{T}}\right]_{i j}^{e l}=\int_{\Omega^{e l}} \lambda\left(\nabla_{1} N_{i} \nabla_{1} N_{j}+\nabla_{2} N_{i} \nabla_{2} N_{j}+\nabla_{3} N_{i} \nabla_{3} N_{j}\right) d v, \quad i, j=\overline{1, N b} .
$$

Here $N b$ is a number of nodes of the finite element; $N_{i}, N_{j}$ are the functions of the form [9].

\section{Numerical results obtained}

Using the suggested method, the stressed state of the $60 \times 6$ tube (made of steel 20) of the boiler unit has been investigated under the influence of the internal working pressure $p=15.5 \mathrm{MPa}$ and under different temperature variations in the thickness of the tube.

Physical and mechanical characteristics of the material were taken as follows: $E=187 \cdot 10^{3} \mathrm{MPa}$; $\nu=0.274 ; \alpha_{t}=13.4 \cdot 10^{-4} 1 /{ }^{\circ} \mathrm{C}[8]$ that meet the operating conditions (operating pressure $15.5 \mathrm{MPa}$ in the temperature $350^{\circ} \mathrm{C}$ ). 
In Fig. 2, the distribution of intensities of the stresses is shown in the thickness of the pipe at the site of the largest thinning, when its length is sufficient $\left(l_{1}=0.3 \mathrm{~m} ; l_{2}=0.4 \mathrm{~m}\right.$ ); $L=1 \mathrm{~m}$ (further increase in the length of the thinning does not affect the distribution and magnitudes of stresses in the thinnest part of the damaged pipe).

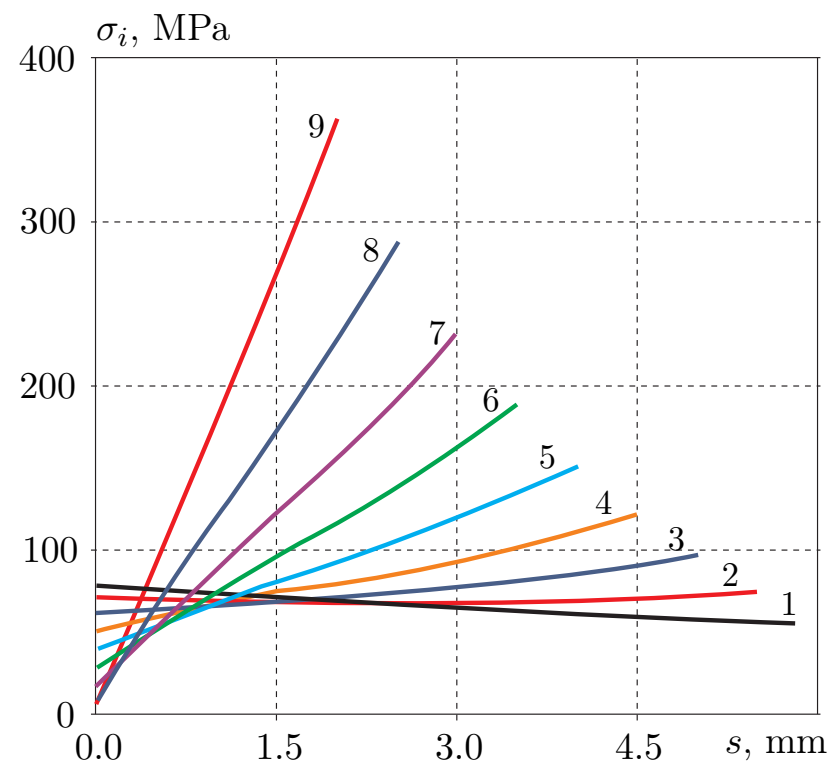

Fig. 2. Distribution of stress intensities in the thickness of the cylinder at the thinnest site with thinning 0 (curve 1); 0.5 (2); 1 (3); 1.5 (4); 2 (5); $2.5(6) ; 3$ (7); $3.5(8) ; 4(9) \mathrm{mm}$.

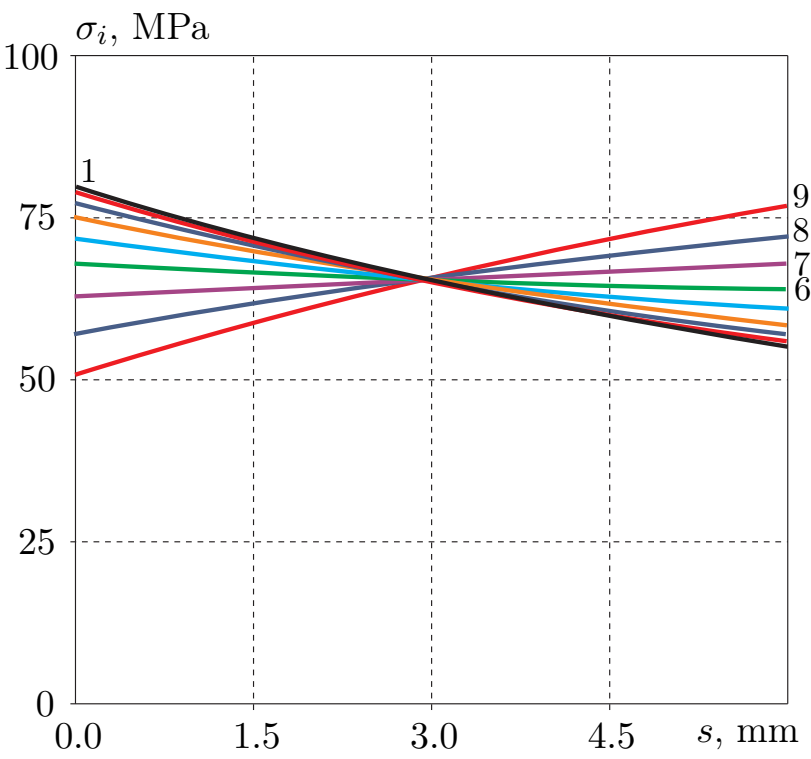

Fig. 4. Distribution of stress intensities in the thickness of the cylinder in the zone, opposite to the thinnest site, for constant thickness (curve 1) and for thinning from 0.5 to $4 \mathrm{~mm}$ (with the $0.5 \mathrm{~mm}$ step).

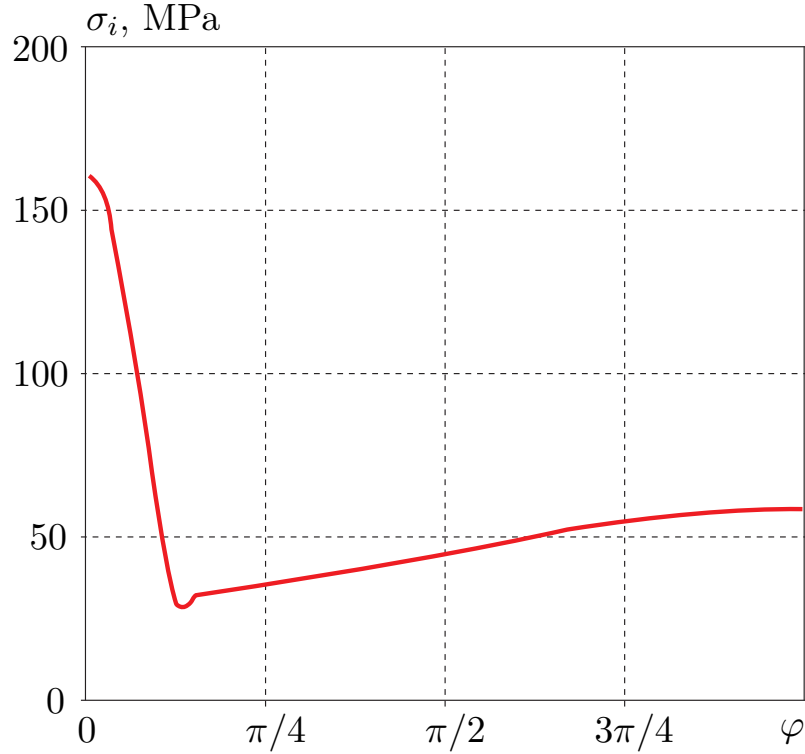

Fig. 3. Distribution of stress intensities on the outer surface of the cylinder along the corner in the direction from the thinnest site $(3.8 \mathrm{~mm})$.

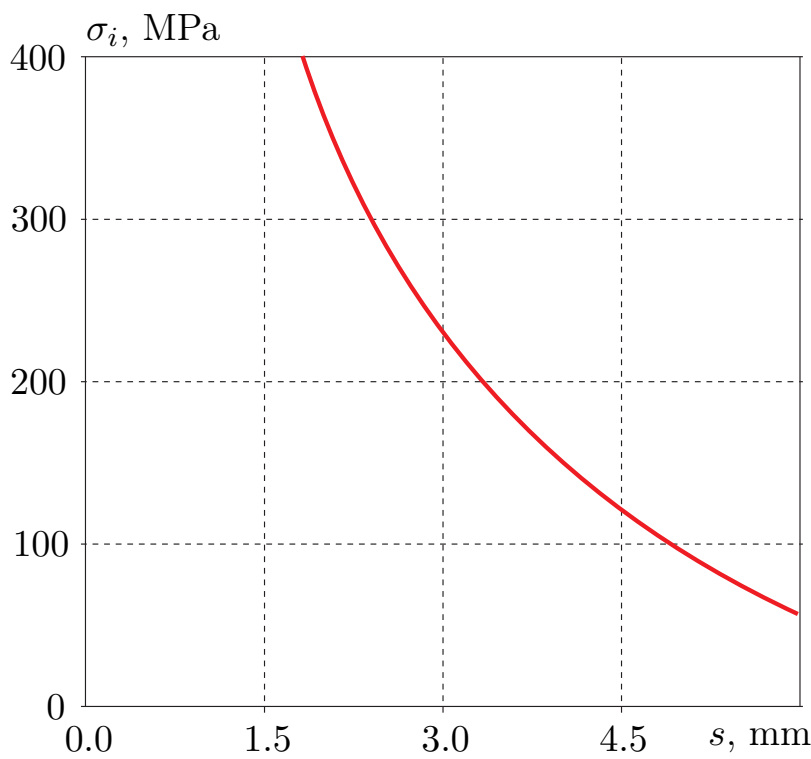

Fig. 5. Dependence of maximum values of stress intensities on the thickness of the cylinder at the site of maximum thinning (loading: internal pressure 15.5 $\mathrm{MPa}$ at $\left.350^{\circ} \mathrm{C}\right)$.

As you can see, in the undamaged tube, the maximum stress occurs on its inner surface. In the course of its thinning, the pattern is gradually changing, and when thinnings exceed $1 \mathrm{~mm}$, the maximum stresses appear on the outer surface of the tube. This result is qualitatively different from what we obtain when using the standard industrial technique. 
In Fig. 3, the distributions of stress intensities on the outer surface of the cylinder along the angular coordinate $\varphi$ (see Fig. 1) in the direction from the thinnest site $\left(s_{\min }=3.8 \mathrm{~mm}\right)$ are shown. The maximum stresses occur in the zone of the greatest thinning.

In Fig. 4, the distributions of stress intensities in the thickness in the zone opposite to the thinnest area are shown. Thus, we see that the magnitude of the stresses in this area weakly depends on the depth of the damage.

In Fig. 5, we can observe the dependence of the maximal values of stress intensities in the thickness at the site of maximum thinning. On the basis of this dependence, one can determine the minimum thickness of the tube wall, for which the maximum stresses do not exceed the permissible level. In particular, if the permissible stresses attain the magnitude $166.4 \mathrm{MPa}$ (the plasticity limit of steel at $350^{\circ} \mathrm{C}[8]$ ), the minimum permissible wall thickness of the tube in the zone of thinning is $3.8 \mathrm{~mm}$. the tube material under the assump-

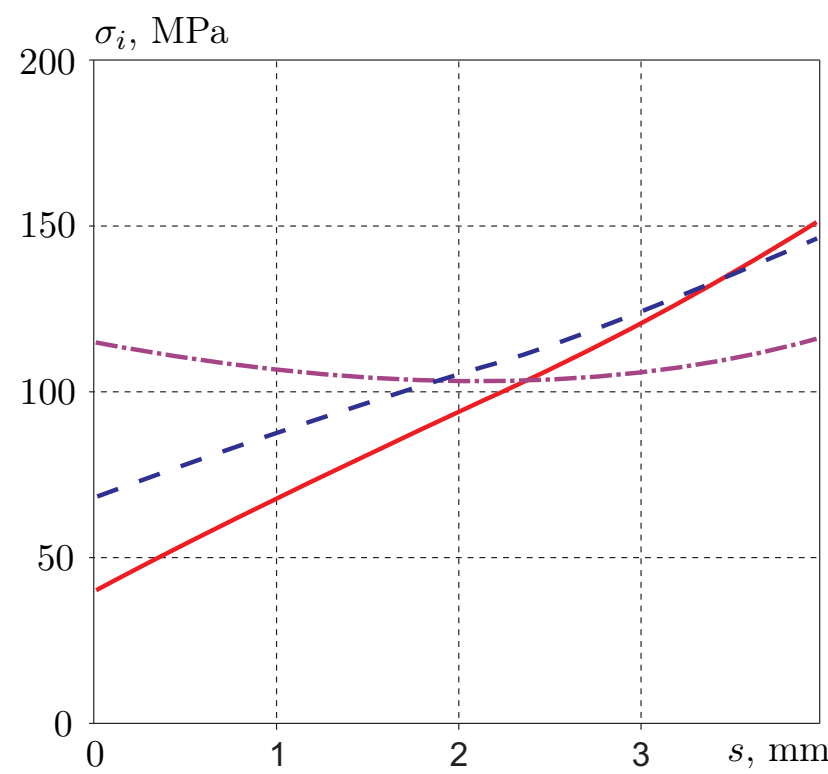

Fig. 6. Distribution of stress intensities in the thickness at the thinnest site $(4 \mathrm{~mm})$ for a force load only (solid curve), as well as in the presence of a gradient of temperature in the thickness of 8 (dashed curve) and $30^{\circ} \mathrm{C}$ (dot-dashed curve). tion of linear relationships between stresses and deformations is attained for the thickness $1.85 \mathrm{~mm}$. Taking into account the plastic properties of the steel 20 , the value of $400 \mathrm{MPa}$ will be attained even for a smaller thickness, which can be determined from the real deformation curve of this material.

On the basis of the conducted research it has been established that the minimum length of the thinnest area, the increase of which does not affect the maximum stresses, is $10-12 \mathrm{~cm}$. Reduction of the length of the damaged area with a given depth of damage leads to a decrease in maximum stresses.

Analysis of the solutions, taking into account the temperature load of the tube, has shown that the differences in temperature under the external heating during stationary operation somewhat reduces the total stresses. Fig. 6 illustrates the distribution of the stresses intensities in the thickness at the site of the largest thinning $\left(s_{\min }=4 \mathrm{~mm}\right)$ for the only action of the working pressure and two drops of temperature in vicinity of $350^{\circ} \mathrm{C}$ and operating pressure. As we see, due to the differences in temperature between the surfaces, it is possible to achieve, in addition, a decrease in the minimum thickness of the pipe (from $3.8 \mathrm{~mm}$ to $3 \mathrm{~mm}$ for the $30^{\circ} \mathrm{C}$ temperature difference and from $3.8 \mathrm{~mm}$ to $3.65 \mathrm{~mm}$ for the $10^{\circ} \mathrm{C}$ temperature difference).

\section{Conclusions}

1. Based on the equations of the three-dimensional theory of elasticity without a priori simplifying assumptions about homogeneous thinning of screen tubes, a method for determining the stressed state of screen tubes with operational damages on the external surface under the given working load conditions has been developed.

2. Within the framework of the suggested approach, dependencies between the maximum stresses and the geometric parameters of the thinned pipe section are constructed. On the basis of the established dependencies, one can determine the minimum thickness of the pipe wall, for which the operating stress does not exceed a given permissible level. It is shown that when thinning is greater $1 \mathrm{~mm}$, the maximum stresses occur on the outer surface of the pipe at the site of its maximum thinning (while for thinning up to $1 \mathrm{~mm}$ they occur on the inner surface). For the lengths of the damaged area more than $10 \mathrm{~cm}$, the maximum stresses in the zone of thinning of the pipe are uniquely determined by the depth 
of the damage, i.e., for the lengths $10,20,30,40 \ldots \mathrm{cm}$ for the same depths of damage, the maximum stresses practically coincide and do not depend on length.

3. If the yield strength of the material of screen tubes (steel 20: $166.4 \mathrm{MPa}$ in the temperature $350^{\circ} \mathrm{C}$ ) is taken as the permissible level of stresses, then the minimum permissible wall thickness of the pipe in the middle zone of the damaged area is $3.8 \mathrm{~mm}$. Since steel 20 is material with deformation strengthening and under operating conditions has ultimate strength about $400 \mathrm{MPa}$, then for the wall thickness of $3.8 \mathrm{~mm}$, the strength factor against fracture will be 2.4 . The ultimate strength of the pipe $400 \mathrm{MPa}$, based on the calculations within the model of the elastic body, will be attained for the thickness $1.85 \mathrm{~mm}$.

4. The change of temperature in the thickness of the wall of the pipe under its external heating causes compressive stresses in the outer surface layer, which reduce the level of total tensile stresses from the internal pressure. As the temperature difference decreases when the operation transits to the stationary mode, its effect on the decrease of the level of maximum tensile stresses decreases.

5. The industrial testing of the theoretical results of this work at the Burshtyn TPS has shown that they can be used to create new domestic branch normative documents on the estimation of the state and residual life of the elements of power equipment.

[1] Mechanics of fracture and strength of materials. Reference book, Vol. 8. Edit. by V. V. Panasyuk. Kyiv, Publishing House "Academiperiodica" (2005), (in Ukrainian).

[2] Melekhov R. K., Pokhmursky V.I. Construction materials of power equipment. Kyiv, Naukova Dumka (2003), (in Ukrainian).

[3] Demidov S. P. Theory of elasticity. Moscow, Vysshaya Shkola (1979), (in Russian).

[4] Kupradze V. D. Methods of potential in the theory of elasticity. Moscow, Fizmatgiz (1963), (in Russian).

[5] Mikhlin S. G. Variational methods in mathematical physics. Moscow, Nauka (1979), (in Russian).

[6] Nowacki W. Dynamic Problems of Thermoelasticity. Springer Netherlands (1975).

[7] Rabotnov Yu. N. Mechanics of a deformable solid. Moscow, Nauka (1979), (in Russian).

[8] Properties of steels and alloys used in boiler-turbine construction. Guidelines. (16). Part One, edit. by L. Ya. Lieberman, M. I. Peysihis. Leningrad, ONTI CKTI named after I. I. Polzunov (1966), (in Russian).

[9] Sakharov A. S., Altenbach I. The finite element method in solid mechanics. Kyiv, Vyscha Shkola (1982), (in Russian).

[10] Zienkiewicz O. C., Taylor R. L. Finite Element Method, Vol. 1. The Basis. London, Butterworth Heinemann (2000). 


\title{
Оцінка придатності екранних труб з пошкодженнями до подальшої експлуатації на основі результатів математичного моделювання
}

\author{
Дробенко Б., Будз С. \\ Інститут прикладних проблем механіки і математики ім. Я. С. Підстригача НАН Украӥни, \\ вул. Наукова, З-б, Лъвів, 79060, Украӥна
}

Здійснено комп'ютерне моделювання процесів деформування екранних труб котлоагрегатів теплоелектростанцій з потоншенням стінок внаслідок інтенсивного впливу топкових газів. Побудовано залежності між максимальними напруженнями в екранних трубах з експлуатаційними потоншеннями і геометричними параметрами пошкоджених ділянок труб, що дають змогу визначити мінімальну товщину труб, за якої експлуатаційні напруження не перевищують заданого допустимого рівня. Встановлено мінімальну допустиму товщину труби в серединній зоні пошкодженої ділянки. Показано, що температурні напруження в трубі за ії зовнішнього обігрівання дещо компенсують силові напруження від внутрішнього тиску.

Ключові слова: математичне та комп'ютерне моделювання, труби котлоагрегатів, оцінка придатності до експлуатації, напружений стан, рачіональні геометричні параметри.

2000 MSC: 74A10, 74B10

удк: $539.3,518.61,658.589$ 